\title{
cNEUPRO: Novel Biomarkers for Neurodegenerative Diseases
}

\author{
Philipp Spitzer, ${ }^{1}$ Hans Wolfgang Klafki, ${ }^{1}$ Kaj Blennow, ${ }^{2}$ \\ Luc Buée, ${ }^{3,4,5}$ Hermann Esselmann, ${ }^{1}$ Sanna-Kaisa Herruka, ${ }^{6}$ \\ Connie Jimenez, ${ }^{7}$ Peter Klivenyi, ${ }^{8}$ Piotr Lewczuk, ${ }^{9}$ \\ Juan Manuel Maler, ${ }^{9}$ Katrin Markus, ${ }^{10}$ Helmut E. Meyer, ${ }^{11}$ Chris Morris, ${ }^{12}$ \\ Thorsten Müller, ${ }^{10}$ Markus Otto, ${ }^{13}$ Lucilla Parnetti, ${ }^{14}$ Hilkka Soininen, ${ }^{6}$ \\ Susanna Schraen, ${ }^{3,4,5}$ Charlotte Teunissen, ${ }^{15}$ \\ Laszlo Vecsei, ${ }^{8}$ Henrik Zetterberg, ${ }^{2}$ and Jens Wiltfang1
}

${ }^{1}$ Laboratory for Molecular Neurobiology, Department of Psychiatry and Psychotherapy, University of Duisburg-Essen, LVR-Klinikum Essen, Virchowstraße 174, 45147 Essen, Germany

${ }^{2}$ Department of Psychiatry and Neurochemistry, Institute of Neuroscience and Physiology,

The Sahlgrenska Academy at the University of Gothenburg, 43180 Mölndal, Sweden

${ }^{3}$ Inserm U837, 1 Place de Verdun, 59045 Lille, France

${ }^{4}$ Faculte de Medicine, Université Lille-Nord de France, UDSL, rue Paul Duez, 59800 Lille, France

${ }^{5} \mathrm{CHU}$, bd. Pr J. Leclerc, 59037 Lille, France

${ }^{6}$ Department of Neurology, Institute of Clinical Medicine, University of Eastern Finland,

Ylipistonranta 1C, 70211 Kuopio, Finland

${ }^{7}$ OncoProteomics Laboratory, Department of Medical Oncology, VU University Medical Center, De Boelelaan 1117, 1081 HV Amsterdam, The Netherlands

${ }^{8}$ Department of Neurology, University of Szeged, P.O. Box 427, 6701 Szeged, Hungary

${ }^{9}$ Department of Psychiatry and Psychotherapy, University of Erlangen, Schwabachanlage 6,

91054 Erlangen, Germany

${ }^{10}$ Functional Proteomics, Medizinisches Proteom-Center, Ruhr-University Bochum, Universitätsstraße 150, 44780 Bochum, Germany

${ }^{11}$ Medical Proteomics/Bioanalytics, Medizinisches Proteom-Center, Ruhr-University Bochum, Universitätsstraße 150, 44780 Bochum, Germany

${ }^{12}$ Medical Toxicology Centre, Institute for Ageing and Health, Institute of Neurosciences, University of Newcastle,

Wolfson Unit, Claremont Place, Newcastle upon Tyne NE2 4AA, UK

${ }^{13}$ Department of Neurology, University of Ulm, Steinhövelstraße 1, 89075 Ulm, Germany

${ }^{14}$ Clinica Neurologica, Università di Perugia, Ospedale S. Maria della Misericordia, 06156 Perugia, Italy

${ }^{15}$ Department of Clinical Chemistry, VU University Medical Center, P.O. Box 7057, 1007 MB Amsterdam, The Netherlands

Correspondence should be addressed to Philipp Spitzer, philipp.spitzer@lvr.de

Received 14 April 2010; Accepted 5 July 2010

Academic Editor: Tuula R. M. Pirttila

Copyright ( 2010 Philipp Spitzer et al. This is an open access article distributed under the Creative Commons Attribution License, which permits unrestricted use, distribution, and reproduction in any medium, provided the original work is properly cited.

"clinical NEUroPROteomics of neurodegenerative diseases" (cNEUPRO) is a Specific Targeted Research Project (STREP) within the sixth framework program of the European Commission dedicated to the search for novel biomarker candidates for Alzheimer's disease and other neurodegenerative diseases. The ultimate goal of cNEUPRO is to identify one or more valid biomarker(s) in blood and CSF applicable to support the early and differential diagnosis of dementia disorders. The consortium covers all steps required for the discovery of novel biomarker candidates such as acquisition of high quality CSF and blood samples from relevant patient groups and controls, analysis of body fluids by various methods, and finally assay development and assay validation. Here we report the standardized procedures for diagnosis and preanalytical sample-handling within the project, as well as the status of the ongoing research activities and some first results. 


\section{Introduction}

The diagnosis of Alzheimer's Disease (AD) is currently based primarily on clinical symptoms. Whereas the sensitivity of the clinical diagnosis for possible and probable Alzheimer Dementia according to National Institute of Neurological and Communicative Disorders and Stroke and the Alzheimer's Disease and Related Disorders Association (NINCDS-ADRDA) criteria is over $80 \%$, its specificity is rather low [1]. The term mild cognitive impairment (MCI) was introduced for subjects who complain about verifiable cognitive disturbances but who show a preserved general cognitive functioning and no impairment in the activities of daily living [2]. These patients can be further subdivided into those with an impaired memory function (amnestic $\mathrm{MCI}$ ) and those whose memory is preserved but who show disturbances of language, executive function, or visualspatial skills (Nonamnestic MCI) [2]. If only one of the above-mentioned cognitive domains is impaired, patients are called single-domain MCI; if two or more domains are affected, they are referred to as multidomain MCI. Although the term MCI is solely descriptive and allows no conclusion on the aetiology, the classification allows some prediction of the course of the disease. For amnestic MCI patients, the risk to convert to Alzheimer's Dementia is $10-15 \%$ per year [3]. Yet, an accurate early diagnosis in MCI patients or even a predictive diagnosis in individuals without cognitive disturbances is still virtually impossible. As there is evidence that pathological biochemical changes start many years before the occurrence of functional symptoms, identification of biological markers in individuals with earlystage dementia is the most promising way to facilitate a predictive diagnosis [4-6].

Improving the early and predictive diagnosis of $\mathrm{AD}$ is of paramount importance if, in the future, preventive and disease-modifying therapies become available. In this regard, enormous efforts are under way. Although most therapies failed to show efficacy in Phase III trials, there are still some promising approaches like $A \beta$ lowering compounds, inhibitors of inflammation, inhibitors of tau phosphorylation and aggregation, and compounds interfering with cholesterol metabolism under investigation [7]. Although the brain has some limited regenerative capacity, neurons are still difficult to replace $[8,9]$. Therefore, it is clear that maximal benefit for the patients can be expected when the treatment can be initiated as early as possible in the course of the disease. Furthermore, biologically valid and clinically accurate biomarkers may serve in the development of novel therapeutic strategies and may provide important information in clinical trials of therapies [10].

Well-documented biomarkers for $\mathrm{AD}$ in cerebrospinal fluid (CSF) include alterations in $\mathrm{A} \beta_{1-42}$, total-tau, and phospho-tau [10]. Importantly, these particular changes are detectable in early dementia stages as well as in individuals with mild cognitive impairment (MCI) who are at high risk of conversion to $\mathrm{AD}$ [11]. When analyzed in wellcharacterized clinical samples, the measurement of $A \beta_{1-42}$, tau, and phospho-tau in cerebrospinal fluid generally allows the diagnosis of $\mathrm{AD}$ and even the prediction of the conversion from MCI to AD with a specificity and sensitivity of about $85 \%$ [12]. However, some report a lower sensitivity of below $50 \%$ for single biomarkers when these biomarkers are measured as part of a routine diagnostic test in a memory clinic [13]. This drop in sensitivity can be explained by the fact that in clinical practice the reference cohort is not a group of cognitively healthy individuals but consists of patients with other neurodegenerative and neurologic diseases who may also have slightly elevated total-tau, phospho-tau, or $A \beta_{1-42}$ levels [13]. The application of these markers in the differential diagnostic of neurodegenerative diseases therefore proves to be particularly problematic [14]. Consequently, there is a need for additional and more sensitive CSF biomarkers for the early and differential diagnosis of Alzheimer's Disease.

There is the additional problem of lumbar puncture to obtain CSF, since although the rate of complications during and after lumbar puncture is below $2-4 \%$ and restricted to mild to moderate postlumbar puncture headache [15-18], it must still be seen as invasive method for which special precautions must be taken. Consequently, there is a pressing need for new biomarkers in more easily accessible bodyfluids such as peripheral blood.

Clinical proteomics is a fast developing field dedicated to the search for new biomarkers applicable to support the clinical diagnosis [19]. At present, a number of potential new biomarker-candidates for $\mathrm{AD}$ have been reported from proteomic studies $[20,21]$; unfortunately, however, the published data is often contradictory and in many cases, a solid reassessment by other methods and with independent samples is required [19].

Taking this into account, the EU-project Clinical Proteomics for Neurodegenerative Diseases (cNEUPRO) is not only dedicated to the detection of potential new biomarker candidates for neurodegenerative diseases in CSF and blood, but also to the implementation of in-depth reassessments and validation studies. Finally, promising biomarker candidates will be studied for their suitability as routine test analytes by prototype assays.

\section{2. cNEUPRO: The Consortium, Goals, and Workflow}

cNEUPRO (http://www.cneupro.eu/) is a Specific Targeted Research Project (STREP) within the sixth framework program of the European Commission. It started in April 2007 and is coordinated by Jens Wiltfang, University of Duisburg-Essen. For the general aims of cNEUPRO, (see Box 1). The consortium consists of 14 academic partners (University of Duisburg-Essen, Centre Hospitalier Universitaire de Montpellier, Sahlgrenska Academy at the University of Gothenburg, VU University Medical Center, University of Ulm, University of Newcastle upon Tyne, University of Aveiro, University of Szeged, University of Perugia, RuhrUniversity Bochum, Heinrich Heine University of Duesseldorf, University of Eastern Finland Kuopio, Institut de la Santé et de la Recherche Médicale, University of Erlangen) as 
The general AIMS of cNEUPRO are:

(i) Detection of new biomarkers for the early, predictive and differential diagnosis of neurodegenerative diseases in CSF and blood

(ii) Development of new diagnostic assays for the early and predictive diagnosis of neurodegenerative diseases in CSF and blood

(iii) Contribution to the standardization of neurochemical dementia diagnosis

(iv) Establishment of two neurochemical dementia diagnosis reference-centers in Hungary and Portugal

Box 1: General aims of cNEUPRO.

well as four small to medium enterprises. (Matrix Advanced Solutions Germany GmbH, MicroDiscovery GmbH, Protagen, BioGenes $\mathrm{GmbH}$ ).

cNEUPRO integrates almost all different levels of biomarker research: the primary phase involves the comprehensive clinical characterization of patients and standardized sample-acquisition and handling by specialized geriatric psychiatrists and neurologists. These samples are subsequently used in the search for candidate biomarkers, their biochemical identification by mass spectrometry, and their reassessment in a second, independent set of high quality samples. Finally, the identified biomarkers will be integrated into novel prototype assays (Figure 1).

The research within cNEURPO concentrates on individuals diagnosed with MCI at baseline who subsequently either developed AD, other dementias, or who did not progress to dementia. As the samples had been taken at baseline, clinical information obtained during follow-up allows the identification of predictive biomarker candidates retrospectively. In addition, clinical samples from patients with early $\mathrm{AD}$ at baseline or other dementias in the early stages are also included in the analysis.

In the search for new biomarker candidates in CSF or blood, hypothesis-free proteomic approaches such as ureabased gel electrophoresis, Multidimensional liquid chromatography, combined with two-dimensional differential gel electrophoresis (2D-DIGE), several mass spectrometric methods (e.g., SELDI-TOF, MALDI-TOF, nanoLC-MALDITOF/TOF, nanoLC-ESI, nanoLCQFTMS), and array-based methods are conducted. Additionally, specific and potentially interesting molecules are studied in detail in the sense of "hypothesis-driven approaches". The most promising biomarker candidates will be selected with the aid of biostatistical tools. Where applicable, published information in terms of the biological function or a possible role of selected candidates in the pathophysiology of AD will also be considered. The selected candidates will be reassessed with a further independent high quality clinical sample of age- and sex-matched patients and controls and with assays allowing for intermediate sample throughput and quantitative comparisons. For those biomarker candidates that can be successfully validated, cNEUPRO will devise novel polyand monoclonal antibodies. Finally the biomarkers will be integrated into novel ELISA-type assays and, if appropriate, in Multiplex-Assays.

An essential prerequisite for a successful multicenter biomarker-discovery study is the standardization of the

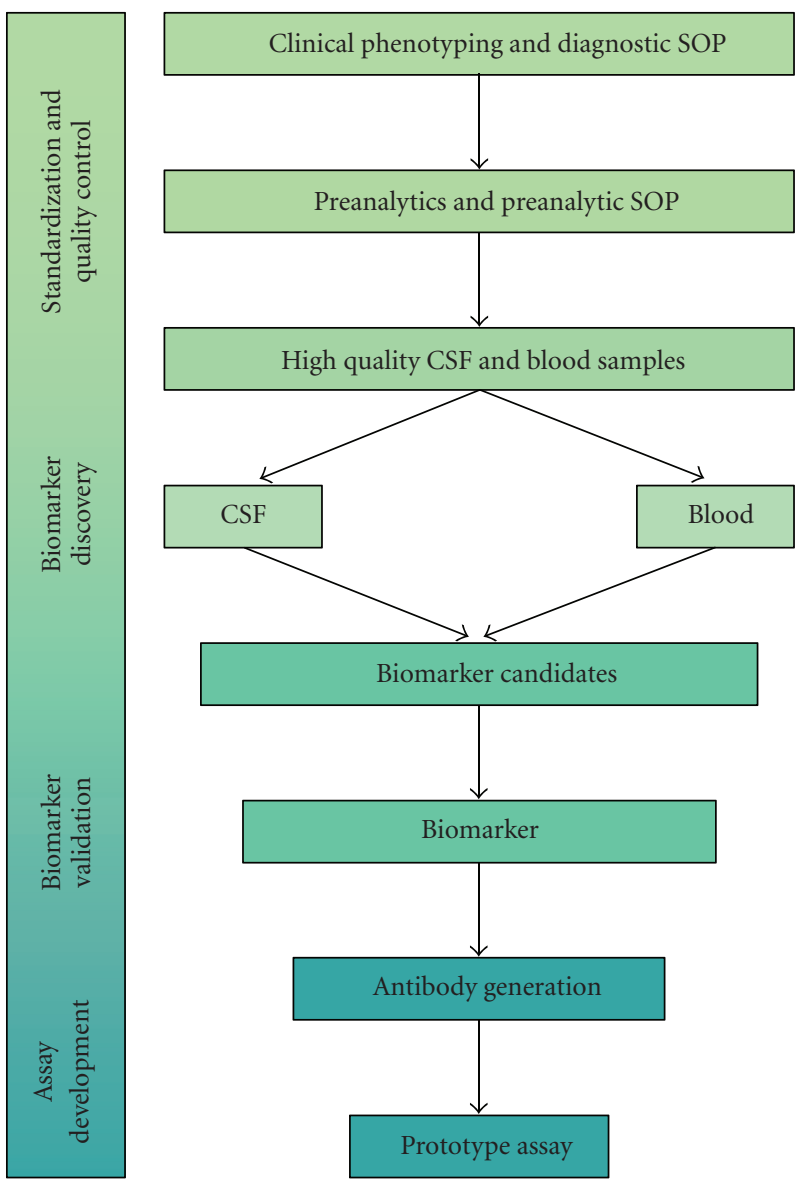

FIGURE 1: Workflow within the project.

clinical diagnostics, the preanalytical sample handling procedures, and the measurements of the known biomarkers totaltau, phospho-tau, and $\mathrm{A} \beta_{1-42}$ in CSF. To this end, two neurochemical dementia diagnosis reference centers in Hungary and Portugal are currently being established, and European standard operating procedures for clinical diagnostics and preanalytical sample handling have been defined.

\section{Current State and First Results of cNEUPRO}

3.1. Neurochemical Dementia Diagnosis-Reference Center in Hungary Launched. In Hungary, 42 Dementia Centers are responsible for the diagnosis and treatment of demented 
Diagnostic standard operating procedure

(i) $\mathrm{AD}$ is diagnosed according to the NINCDS-ADRDA criteria [27].

(ii) DLB is diagnosed according to the criteria of McKeith [28].

(iii) $\mathrm{VaD}$ is diagnosed according to the NINCDS-AIREN criteria [29].

(iv) FTLD is diagnosed according to the consensus criteria of Neary [30].

(v) CJD is diagnosed according to the WHO criteria (Geneva 1998).

(vi) CDR is used for staging of Dementia [31].

(vii) MMSE is used for grading of dementia [32].

(viii) A follow-up of two years must be retrievable.

(ix) Additional neuropsychological testing is desirable but not mandatory.

(x) A CT or MRI scan must be available.

(xi) The ApoE genotype should be determined.

(xii) CSF should be obtained and the concentration of $\mathrm{A} \beta_{1-42}$, tau and phospho-tau should be determined.

Box 2: Diagnostic standard operating procedure. $\mathrm{AD}=$ Alzheimer's Disease, $\mathrm{DLB}=$ Dementia with Lewy-bodies, VaD $=$ Vascular Dementia, $\mathrm{FTLD}=$ frontotemporal lobar degeneration, $\mathrm{CJD}=$ Creutzfeldt-Jacob Disease, $\mathrm{CDR}=$ Clinical Dementia Rating Scale, MMSE $=$ Mini Mental Status Examination. References in the box: [27-32].

patients. Before 2009, the CSF analysis of $\mathrm{A} \beta_{1-42}$, total-tau, and phospho-tau to support dementia diagnostics was not possible for these centers. As one of the aims of cNEUPRO, the first reference center for neurochemical dementia diagnosis in Hungary was launched in Szeged. With the support of the cNEUPRO consortium, state-of-the-art diagnostic and methodological standards have been implemented, and the center takes part in an ongoing quality control program organized by Kaj Blennow from Sahlgrenska University Hospital, Mölndal, Sweden. During its first twelve months of operation, the neurochemical dementia diagnosis reference center in Szeged has received a total of 54 CSF samples from 14 different Dementia Centers in Hungary. This neurochemical dementia diagnosis center will now try to provide its service to further Dementia Centers in Hungary and to start collecting samples for scientific purposes.

\subsection{Diagnostic and Preanalytical Standard Operating Proce-} dures. Due to substantial intercenter variations, the reported accuracy of CSF biomarkers is considerably lower in multicenter studies than in single center surveys [22-24]. To this end, a multicenter study, supported by cNEUPRO, provides guidance on how to establish, validate, and audit CSF tau cutoff values using an unbiased, two-stage multicentre strategy [25]. Furthermore, a hands-on workshop was organized by members of the cNEUPRO consortium (paper submitted to the same issue of IJAD). The aim of the workshop was to assess the differences in assay procedures as potential sources of error. During this workshop, 14 groups simultaneously performed the $\mathrm{A} \beta_{1-42}$, total-tau, and phospho-tau assays according to the guidelines of the manufacturer. At least 23 items in assay procedures were identified that varied between the laboratories, including procedures for washing, pipetting, incubation, finishing, and sample handling. Thus, even if centers use the same assays for $\mathrm{A} \beta_{1-42}$, total-tau, and phospho-tau measurement on a regular basis, they do not uniformly adhere to the procedures recommended by the manufacturer. The results of the workshop stress the importance of standardization of assay protocols. To facilitate biomarker research on a multicenter level, standard operating procedures for the clinical diagnosis and the preanalytical sample handling have been defined by the cNEUPRO consortium (Boxes 2 and 3). The standard operating procedures for sample acquisition, handling, and storage defined by cNEUPRO meet the quality standards required for proteomic studies in CSF [19] and are in agreement with the recently published guidelines for CSF collection and biobanking from the BioMS-eu network [26].

\subsection{Investigated CSF Biomarker Candidates for AD Related} to Amyloid Precursor Protein (APP) Processing and Tau Pathology. In the last decade, the levels of A $\beta$ peptides and tau proteins in CSF have gained increasing importance in supporting the clinical diagnosis of $\mathrm{AD}[10,33]$. As no single marker alone allows for a diagnosis with the desired accuracy, several combinations of CSF-biomarkers $\left(\mathrm{A} \beta_{x-42}\right.$, $\mathrm{A} \beta_{x-40}$, total-tau, phospho-tau) have been proposed [12]. For these markers, a diagnostic accuracy of up to $94 \%$ has been achieved in single center studies [12]. Within cNEUPRO, Welge et al. reported a sensitivity and specificity of $88 \%$ in the discrimination of $\mathrm{AD}$ subjects from other dementias and from elderly depressed individuals with cognitive complaints, by combining the measurement of $\mathrm{A} \beta_{1-40}$, $\mathrm{A} \beta_{1-38}$, and phospho-tau [34]. With the use of MALDI-TOF mass-spectrometry for the study of CSF samples from AD patients, an oxidized form of $\mathrm{A} \beta_{1-40}\left(\mathrm{~A} \beta_{1-40}{ }^{\mathrm{ox}}\right)$ was identified. Quantification by SDS-PAGE/western immunoblot revealed elevated $\mathrm{A} \beta_{1-40}{ }^{\text {ox }}$ levels in patients with $\mathrm{AD}$ as compared to probable vascular dementia and controls [35]. Taken together, these pilot studies suggest that besides $\mathrm{A} \beta_{1-42}$, additional variants of $\mathrm{A} \beta$ peptides may turn out to be specifically altered in $\mathrm{AD}$ patients.

Although combinations of these CSF biomarkers were reported to have a high predictive value in single-center studies, their application in multicenter-studies is hampered by relatively high intercenter variations. In an associated multicenter study, including 750 patients with MCI who were 
Preanalytical standard operating procedure for CSF:

(i) Cerebrospinal fluid (CSF) is collected by lumbar puncture (LP). Ventricular CSF can also be included but should be clearly labelled as such.

(ii) CSF is collected in polypropylene tubes.

(iii) A standardised volume $(10-12 \mathrm{~mL})$ is collected.

(iv) Samples contaminated with more than $500 \mathrm{red}$ blood cells $/ \mu \mathrm{L}$ should not be included.

(v) Collected CSF is centrifuged at approximately $1,000-2,500 \mathrm{xg}$ at $+4^{\circ} \mathrm{C}$ or room temperature for 10 minutes within 1 hour after the sampling.

(vi) The supernatant is pipetted off, gently mixed to avoid possible gradient effects and aliquoted in portions in polypropylene tubes.

(vii) The samples are stored at $-80^{\circ} \mathrm{C}$ without having been thawed and re-frozen.

Preanalytical standard operating procedure for serum and plasma:

(i) Serum and plasma are collected by vein puncture.

(ii) Plasma is collected into polypropylene tubes containing EDTA.

(iii) Serum is collected into polypropylene tubes without additives.

(iv) Collected blood samples are centrifuged at approximately $1,000-2,500 \mathrm{xg}$ at $+4^{\circ} \mathrm{C}$ or room temperature for 15 minutes within 2 hour after the sampling.

(v) The supernatant is pipetted off, gently mixed to avoid possible gradient effects and aliquoted in portions in polypropylene tubes.

(vi) The samples are stored at $-80^{\circ} \mathrm{C}$ without having been thawed and re-frozen.

Box 3: Preanalytic standard operating procedures for CSF and blood.

followed for at least two years, the conversion to $\mathrm{AD}$ could be predicted with a sensitivity of $83 \%$ and a specificity of $72 \%$ by the ratio of $A \beta_{1-42} /$ phospho-tau and total-tau. These values are substantially lower than those seen in several single center studies [24]. The highest intercenter variations were reported for $A \beta_{1-42}$. As this is probably due to its high potential to form aggregates and to stick to test tubes, alternative markers related to APP processing have been investigated within cNEUPRO. In an associated multicenter study, $\operatorname{sAPP} \alpha$ and sAPP $\beta$, two proteins secreted in the CSF after the $\alpha$ - or $\beta$ secretase cleavage of APP, were assessed in 188 patients with MCI or mild to moderate AD. In previous studies, $\operatorname{sAPP} \alpha$ and $\mathrm{SAPP} \beta$ were found to be unchanged $[36,37]$ or decreased [38-40] in the CSF of AD patients. Within cNEUPRO, sAPP $\alpha$ and $\mathrm{sAPP} \beta$ levels in CSF of MCI and AD patients with elevated total-tau and reduced $A \beta_{1-42}$ CSF concentrations were compared to those from patients without a respective CSF biomarker profile. Both were found to be higher in the CSF from patients with an $\mathrm{AD}$-indicative biomarker profile [41]. Taken together, these results suggest that $\operatorname{sAPP} \alpha$ and sAPP $\beta$ may be indicators of altered APP expression and/or metabolism. Reports on their value as candidate biomarkers are however so far contradictory.

In a different study which was supported by cNEUPRO, six novel $\mathrm{N}$-terminal APP-fragments with molecular masses of approximately $12 \mathrm{kDa}$ and starting at amino acid 18 of the APP sequence were detected in CSF by mass spectrometry. In a subsequent small pilot study, six of six AD patients and five of five controls could be classified correctly by the combined evaluation of five of the six fragments [42]. Additionally, Immuno-MS analysis of CSF has led to the detection of eleven novel APP fragments, which begin N-terminally to the $\beta$-secretase cleavage site, and end one amino acid before the proposed $\alpha$-secretase cleavage site (APP/A $\beta$ peptides)
[43]. Interestingly, seven of the twelve APP/A $\beta$ peptides were significantly upregulated in $\mathrm{AD}[43]$.

3.4. CSF-Biomarker Candidates for AD Investigated within cNEUPRO, Which Are Not Related to APP Processing or Tau Pathology. One of several kinases that have been suggested to be involved in the abnormal hyperphosphorylation of tau is the MAP-kinase ERK1/2. In a methodological pilot study, ERK $1 / 2$ and its doubly phosphorylated, activated form have been detected in a small number of CSF samples from patients with $\mathrm{AD}, \mathrm{MCI}$, and frontotemporal lobar degeneration (FTLD) [44]. To evaluate the usefulness of ERK $1 / 2$ as a potential novel CSF biomarker, ERK1/2 levels in CSF are currently being studied in a total of $110 \mathrm{CSF}$ samples from partners within the consortium with a chemiluminescent 96 well assay format.

In accordance with a previous report [45], research within cNEUPRO found glial fibrillary acidic protein (GFAP), a marker for astrogliosis, to be increased in CSF of $\mathrm{AD}$ and sporadic Creutzfeldt-Jacob Disease (sCJD) patients. CSF samples of $18 \mathrm{AD}$ patients, $22 \mathrm{sCJD}$ cases, and 18 from nondemented controls were analyzed with the use of a commercially available ELISA. In AD, a remarkable elevation in CSF GFAP levels with no overlap to controls was observed. Although a significant increase in GFAP could be observed in CJD as well, this was not as pronounced as in $\mathrm{AD}$ [46]. Consequently GFAP might have some additive value as part of a biomarker supported diagnosis, although it lacks specificity for AD.

Chronic inflammation associated with oxidative and nitrosative stress is another aspect which is considered to be important in the pathophysiology of $\mathrm{AD}$ [47]. The most common protein markers of oxidative and nitrosative stress are protein-bound carbonyls and 3-nitrotyrosine [48]. An 
increased oxidation of certain proteins and an increased concentration of 3-nitrotyrosine have been reported in tissue [49] and CSF [50-52] of AD patients, but there is also contradictory data indicating no difference between $\mathrm{AD}$ and controls [53]. In a study conducted by members of the cNEUPRO consortium, where the concentrations of 3nitrotyrosine and total protein carbonylation were measured, no change was found in CSF of AD patients [48]. Yet, slightly reduced levels of protein carbonyls were detected in ApoE- $\varepsilon 4$ carriers as compared to ApoE- $\varepsilon 4$ noncarriers [48]. These results suggest that the concentrations of total protein carbonyls and 3-nitrotyrosine are at this stage not suitable to monitor the chronic inflammatory processes related to $\mathrm{AD}$.

\subsection{Investigated CSF Biomarkers for Other Neurodegenerative} Diseases. In addition to promoting the early and predictive diagnosis of $\mathrm{AD}, \mathrm{cNEUPRO}$ is also dedicated to search for new biomarkers to support the diagnosis of other neurodegenerative diseases such as SCJD, FTLD, vascular dementia (VaD), Dementia with Lewy bodies (DLB), Parkinson's Disease (PD), and Parkinson's Disease Dementia (PDD).

Two-dimensional differential gel electrophoresis (2DDIGE) followed by MALDI-TOF mass-spectrometry indicated that CSF from patients with sCJD differed from CSF from patients with other neurological deficits on the basis of several protein spots. Among these, several previously identified surrogate markers of sCJD such as 14-3-3 protein, neuron-specific enolase, and lactate dehydrogenase were identified. Additionally, an unidentified protein of $85 \mathrm{kDa}$ was found to be significantly increased in SCJD patients [54].

In a separate cNEUPRO investigation, SELDI-TOF mass spectrometry was applied in the analysis of CSF from 32 sCJD patients, 32 controls, and 31 patients with other dementias. Ubiquitin, an $8.6 \mathrm{kDa}$ protein involved in protein degradation, was found to be elevated in the CSF of sCJD cases. This could be confirmed by reassessment with western immunoblots. In the study population, the accuracy of a biomarker-based classification of the samples could be significantly improved by including Ubiquitin in addition to tau, and 14-3-3 protein [55]. This finding is in accordance with several previous reports where Ubiquitin was also found to be elevated in the CSF of sCJD patients [56]. As there is also evidence for altered levels of CSF Ubiquitin in AD [5759] and vascular dementia [60], it seems that this observation is related to neurodegenerative processes in general and not to a specific disease. Yet, in the Steinacker study CSF Ubiquitin levels in sCJD were higher than those in other dementias [55]. Therefore, Ubiquitin may still be a good biomarker for sCJD if, as with tau protein [61], diseasespecific cut-off values are applied.

S100B, another astroglial marker, may also be useful to support the diagnosis of sCJD. Within cNEUPRO, S100B was measured in 54 CSF samples from patients with sCJD, AD, and control patients with the use of a commercial ELISA. Supporting previous findings $[62,63]$, S100B was shown to be highly elevated in SCJD with no overlap to the other groups [46]. Others have found elevated S100B in familial CJD cases [64], but also in CSF [65] and serum [66] of AD patients. These findings suggest that more attention might be paid to the use of astroglial markers in supporting the differential diagnosis of dementias [46].

With respect to FTLD, cNEUPRO found elevated mean levels of the TAR DNA-binding Protein 43 (TDP-43) and reduced $\mathrm{A} \beta_{1-42}$ levels $[67,68]$. In line with the reported increased gene expression of TDP-43 in brain tissues [69], elevated $45 \mathrm{kDa}$ TDP-43 levels were found in the CSF of 12 patients with FTLD as compared to 13 nondemented controls by western-immunoblot [67].

In the same sample, the assessment of different $\mathrm{A} \beta$ peptide species, sAPP $\alpha$ and $\operatorname{sAPP} \beta$, by electrochemiluminescence-based multiplex assays indicated no significant difference for $\operatorname{sAPP} \alpha$ and $\operatorname{sAPP} \beta$ between the groups. However, reduced $A \beta_{1-42}$ levels were found in FTLD [68]. These findings are supported by several earlier studies which found CSF-levels of $\mathrm{A} \beta_{1-42}$ in FTLD to be lower than in nondemented controls and higher than in $\mathrm{AD}$ [70-73]. However, there are also contradictory publications, regarding levels of $\mathrm{A} \beta$ species which did not find reduced CSF $\mathrm{A} \beta_{1-42}$ concentrations in FTLD $[74,75]$. Although TDP-43 and fragments of APP processing are currently not suitable as biomarkers because of a large overlap between the different diagnostic groups, these findings may still reflect aspects relevant for understanding the pathophysiology of these disorders.

In an associated study focussed on the biomarker supported differential diagnosis of $\mathrm{AD}, \mathrm{PD}, \mathrm{PDD}$, and $\mathrm{DLB}$, CSF $A \beta_{1-42}$, total-tau, and phospho-tau were measured in the CSF of a total of 80 patients. Although some significant differences in the average biomarker measurements were found between the groups, only $\mathrm{AD}$ patients could be effectively differentiated from patients with other dementias by phospho-tau. For $\mathrm{A} \beta_{1-42}$, total-tau, and phospho-tau, a large overlap between the other neurodegenerative diseases was observed. Interestingly, only in DLB were $A \beta_{1-42}$ and total-tau found to correlate with the duration and the severity of dementia [76]. Consequently, more and better biological markers are needed to support the differential diagnosis of these dementias [77].

A marker with a potential specificity for synucleinopathies may be the lysosomal hydrolase $\beta$-glucocerebrosidase. In addition to a previous report linking a reduced activity of $\beta$-glucocerebrosidase to PD [78], a reduced activity of $\beta$-glucocerebrosidase was specifically found in DLB within cNEUPRO. In CSF from nondemented controls, patients with $\mathrm{AD}$ or FTLD, no differences in $\beta$-glucocerebrosidase activity were found. In contrast, the activity of $\alpha$ mannosidase, another lysosomal hydrolase, was found to be significantly reduced in all investigated neurodegenerative diseases as compared to controls [79]. In order to support the hypothesis that CSF $\beta$-glucocerebrosidase activity might be a novel CSF biomarker of synucleinopathies, the data need to be confirmed in larger studies.

\subsection{Investigated Blood-Biomarker Candidates Related to APP} Processing. Several recent studies aimed at identifying AD biomarkers in blood were specifically targeted at determination of $\mathrm{A} \beta$ peptides in blood plasma or serum [20]. 
Within a cNEUPRO associated substudy of the German Kompetenznetz Demenzen (http://www.kompetenznetzdemenzen.de/), $A \beta_{1-40}$ and $A \beta_{1-42}$ were assessed in blood plasma from 257 individuals with multiplexing technology on the Luminex platform. A statistically significant decrease of the $A \beta_{1-42 / 1-40}$ ratio was found in the plasma of the patients with early $\mathrm{AD}$ and $\mathrm{MCI}$ of $\mathrm{AD}$ type whose clinical diagnoses were backed up by corresponding findings in the CSF [80]. Moreover, the cNEUPRO associated French "Three-City study" found that a reduction of the ratios $\mathrm{A} \beta_{1-42} / \mathrm{A} \beta_{1-40}$ as well as $\mathrm{A} \beta_{x-42} / \mathrm{A} \beta_{x-40}$ was associated with an increased risk of developing dementia within the next two years [81]. In contrast, several other published studies have not reported significant differences in $A \beta$ peptide concentrations in blood plasma between AD patients and controls [82-84]. In summary, there is no definitive conclusion as to whether plasma $A \beta$ reflects the changing level of central amyloid [20]. Due to the substantial interindividual variations and a large overlap between the diagnostic groups, measuring the individual concentrations of $\mathrm{A} \beta$ peptides in plasma is not suitable to support the clinical diagnosis of different dementia disorders. However, there is preliminary evidence that specific forms of $\mathrm{A} \beta$ peptides in plasma prove to be helpful in the differential diagnosis of $\mathrm{AD}$ and other dementias. In a retrospective pilot study which was supported by cNEUPRO, vascular dementia could be differentiated with a sensitivity and specificity of $>80 \%$ from other dementias and depressive controls by the ratio of $\mathrm{A} \beta_{1-38} / \mathrm{A} \beta_{1-40}$ [85].

Currently, highly sensitive assays for the detection of $A \beta$ peptides in blood and CSF are available for $\mathrm{A} \beta_{x-38}, \mathrm{~A} \beta_{x-40}$, and $A \beta_{x-42}$. For a detailed analysis of additional variants of $A \beta$ peptides in blood plasma, a highly sensitive two-dimensional gel separation method was established within cNEUPRO. Using this method, at least 30 different $A \beta$ peptides were observed [86]. Semiquantitative analysis revealed that the peptides $A \beta_{1-40}$ and $A \beta_{1-42}$ accounted for less than $60 \%$ of all $\mathrm{A} \beta$ peptides that were detected by the specific antibody that was used in this study. At least $10 \%$ of the detected $\mathrm{A} \beta$ peptides appear to be $\mathrm{N}$-terminally truncated [86]. One possible source of these $\mathrm{N}$-terminally truncated $\mathrm{A} \beta$ peptides detected in human plasma is mononuclear phagocytes. Cultures of human mononuclear phagocytes were shown to secrete complex $A \beta$ peptide patterns characterized by a high proportion of N-terminally truncated variants [87]. Furthermore, the secretion of $\mathrm{A} \beta$ peptides from human mononuclear phagocytes was differentially regulated in response to cell culture conditions [87] and was elevated in cell cultures of mononuclear phagocytes from $\mathrm{AD}$ patients as compared to controls [88]. Additional work is under way to evaluate several $\mathrm{N}$ - and $\mathrm{C}$-terminally truncated $\mathrm{A} \beta$ peptides in plasma as potential biomarkers for $\mathrm{AD}$.

3.7. Currently Ongoing Research in cNEUPRO. The identification of valid biomarkers in blood is highly desirable because they have the advantage of being easily accessible. The search for potential biomarker candidates in plasma or serum is complicated by the presence of a number of highly abundant proteins. These proteins which are believed to have only small diagnostic potential make up about $90 \%$ of the whole plasma proteome [89]. As a first step towards biomarker discovery in serum, it was shown that the depletion of 12 high abundant serum proteins by immuno affinity chromatography columns resulted in an increased number of detected peaks by subsequent analysis with SELDI-TOF mass spectrometry [90]. In contrast, CSF proteomics for biomarker discovery in neurodegenerative diseases is particularly attractive because of the proximity of CSF to the brain. Again, the removal of highly abundant proteins resulted in an improved detection of low abundant CSF proteins including brain-derived proteins. Additional separation procedures were introduced to account for the large dynamic range of the expression levels and to simplify the analysis of proteolytically generated peptides by mass spectrometry. For a comparative analysis of individual clinical samples and for a relatively in-depth search for potential novel biomarkers, reproducibility is an absolute requirement. Therefore, different multiaffinity depletion methods followed by gelnanoLC-MS/MS and spectral counting have been evaluated for the in-depth, label-free quantitative analysis of CSF. Depletion in spin-filter format, coupled to gel-LC-MS/MS, provided a robust method that yielded $\sim 800$ CSF proteins per analyzed sample, with acceptable reproducibility of protein identification $(71 \%-74 \%$ in technical replicates) and quantification ( $17 \%-18 \% \mathrm{CV}$ on spectral counts). To control for reproducibility, the same workflow was implemented in two separate laboratories within cNEUPRO. This proteomics approach was subsequently applied in both laboratories to the independent analysis of two separate cohorts of 20 individual CSF samples each. In both cohorts the patients were clinically diagnosed, and CSF was taken according to the cNEUPRO standard operating procedures. Both discovery sets of samples included CSF samples from five control subjects, from five subjects with mild cognitive impairment without conversion to $\mathrm{AD}$, from five patients with mild cognitive impairment with conversion to $\mathrm{AD}$ within the follow-up of 2 years, and five patients with $\mathrm{AD}$. Both datasets contained $\sim 1100$ identified proteins with a total of $\sim 1600$ unique CSF proteins in the common dataset and an overlap of $\sim 500$ between the two laboratories. The biostatistical analysis is currently on-going to select the most promising candidates for a reassessment by targeted mass spectrometry and antibody-based methods in a larger set of samples.

\section{Conclusion}

Within the first two years, cNEUPRO confirmed sAPP, various $A \beta$ peptide variants, GFAP, S100B, and ubiquitin as biomarker candidates known from previous studies. Additionally, further APP fragments were discovered and TDP-43 as well as $\beta$-glucocerebrosidase and ERK 1/2 were proposed as potential novel candidate biomarkers for the early and differential diagnosis of neurodegenerative diseases (Table 1). Because of the high complexity of the blood proteome and probably because of its distance from brain pathology, novel biomarkers in serum or plasma are still elusive. To promote biomarkers in support of the clinical diagnosis of neuropsychiatric disorders in Europe, cNEUPRO devised European standard operating procedures 
TABLE 1: List of candidate biomarkers investigated in the context of cNEUPRO. CON: control patient, AD: Alzheimer's Disease, OD: other dementia, VaD: vascular dementia, MCI: Mild cognitive impairment, sCJD: sporadic Creutzfeldt-Jacob Disease, FTLD: Frontotemporal lobar degeneration, ALS: Amyotrophic Lateral Sclerosis, DLB: Dementia with Lewy bodies.

\begin{tabular}{|c|c|c|c|c|c|c|}
\hline Biomarker candidate & Context/Function & Method & Patients & $n$ & Result & Ref. \\
\hline \multicolumn{7}{|c|}{ Investigated CSF candidate biomarkers for AD related to APP processing } \\
\hline \multirow{3}{*}{$\mathrm{A} \beta_{1-42 / 1-38}$ ratio } & \multirow{3}{*}{ APP processing } & \multirow{3}{*}{ ELISA/MSD } & $\mathrm{CON}$ & 30 & \multirow{3}{*}{ Reduced in $\mathrm{AD}$} & \multirow{3}{*}[34]{} \\
\hline & & & $\mathrm{AD}$ & 44 & & \\
\hline & & & OD & 87 & & \\
\hline \multirow{3}{*}{$\mathrm{A} \beta_{1-40}{ }^{\mathrm{ox}}$} & \multirow{3}{*}{ APP processing } & \multirow{3}{*}{ Western blot } & $\mathrm{CON}$ & 30 & \multirow{3}{*}{ Elevated in $\mathrm{AD}$} & \multirow{3}{*}[35]{} \\
\hline & & & $\mathrm{AD}$ & 30 & & \\
\hline & & & $\mathrm{VaD}$ & 37 & & \\
\hline \multirow{3}{*}{ sAPP } & \multirow{3}{*}{ APP processing } & \multirow{3}{*}{ Luminex } & MCI & 81 & Elevated sAPP $\alpha / \beta$ in & \multirow{3}{*}[41]{} \\
\hline & & & $\mathrm{AD}$ & 69 & patients with elevated & \\
\hline & & & $\mathrm{OD}$ & 38 & tau and reduced $\mathrm{A} \beta_{1-42}$ & \\
\hline \multirow{2}{*}{$\mathrm{APP} / \mathrm{A} \beta$} & \multirow{2}{*}{ APP processing } & \multirow{2}{*}{ LC-MS } & $\mathrm{CON}$ & 3 & \multirow{2}{*}{ Elevated in $\mathrm{AD}$} & \multirow[t]{2}{*}[43]{} \\
\hline & & & $\mathrm{AD}$ & 3 & & \\
\hline \multirow{4}{*}{$12 \mathrm{kDa}$ sAPP } & \multirow{4}{*}{ APP processing } & LC-FTICR-MS & $\mathrm{CON}$ & 6 & Elevated in $\mathrm{AD}$ & {$[42]$} \\
\hline & & & $\mathrm{AD}$ & 5 & & \\
\hline & & Western blot & $\mathrm{CON}$ & 6 & Elevated in $\mathrm{AD}$ & {$[42]$} \\
\hline & & 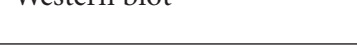 & $\mathrm{AD}$ & 6 & Liv vacturitio & \\
\hline Investigated CSF can & didate biomarkers for $\mathrm{AD}$ & not related to APP processin & & & & \\
\hline & & & $\mathrm{CON}$ & 12 & & \\
\hline GFAP & Marker for astrogliosis & ELISA & $\mathrm{AD}$ & 18 & Elevated in $\mathrm{AD}$ & {$[46]$} \\
\hline & & & sCJD & 22 & & \\
\hline Total protein & Neuro-inflammation & FIJSA & $\mathrm{CON}$ & 18 & No difference between & {$[48]$} \\
\hline carbonylation & 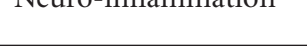 & LLION & $\mathrm{AD}$ & 22 & $\mathrm{AD}$ and $\mathrm{CON}$ & \\
\hline 3-nitrotyrosine & Neuro-inflammation & ELISA & $\mathrm{CON}$ & 18 & No difference & {$[48]$} \\
\hline & & & $\mathrm{AD}$ & 22 & between $\mathrm{AD}$ and $\mathrm{CON}$ & \\
\hline & & & MCI & 9 & & \\
\hline ERK $1 / 2$ & MAP-Kinase & $\begin{array}{l}\text { western blot/electrochemi- } \\
\text { luminescence }\end{array}$ & $\mathrm{AD}$ & 4 & Pilot study, no statistics & {$[44]$} \\
\hline & & & FTLD & 2 & & \\
\hline Investigated CSF can & didate biomarkers for oth & er dementias & & & & \\
\hline & & & $\mathrm{CON}$ & 12 & & \\
\hline S100B & Marker for astrogliosis & ELISA & $\mathrm{AD}$ & 18 & Elevated in sCJD & {$[46]$} \\
\hline & & & sCJD & 22 & & \\
\hline & & & $\mathrm{CON}$ & 13 & & \\
\hline TDP-43 & DNA binding protein & Western blot & FTLD & 12 & Elevated in FTLD & {$[67]$} \\
\hline & & & ALS & 15 & and ALS & \\
\hline & & & ALS+FTLD & 9 & & \\
\hline & & & $\mathrm{CON}$ & 6 & & \\
\hline $85 \mathrm{kDa}$ protein & Unknown & 2D-DIGE/MALDI-TOF & $\mathrm{AD}$ & 24 & Elevated in sCJD & {$[54]$} \\
\hline & & & sCJD & 36 & & \\
\hline & & & DLB & 6 & & \\
\hline & & & $\mathrm{CON}$ & 32 & & \\
\hline Ubiquitin & Protein degradation & LC-MS/WB & sCJD & 32 & Elevated in sCJD & {$[55]$} \\
\hline & & & OD & 31 & & \\
\hline & & & $\mathrm{CON}$ & 23 & & \\
\hline$\alpha$-Mannosidase & Lysosomal Hydrolase & Enzyme activity assay & $\mathrm{AD}$ & 20 & Reduced in all & [79] \\
\hline & & & FTLD & 20 & dementias & \\
\hline & & & DLB & 17 & & \\
\hline
\end{tabular}


TABle 1: Continued.

\begin{tabular}{|c|c|c|c|c|c|c|}
\hline Biomarker candidate & Context/Function & Method & Patients & $n$ & Result & Ref \\
\hline \multirow{4}{*}{$\beta$-Glucocerebrosidase } & \multirow{4}{*}{$\begin{array}{l}\text { Lysosomal } \\
\text { Hydrolase }\end{array}$} & \multirow{4}{*}{ Enzyme activity assay } & $\mathrm{CON}$ & 23 & & \multirow{4}{*}[79]{} \\
\hline & & & $\mathrm{AD}$ & 20 & Reduced in DLB & \\
\hline & & & FTLD & 20 & & \\
\hline & & & DLB & 17 & & \\
\hline
\end{tabular}

for preanalytical sample handling and established a neurochemical dementia diagnosis reference center in Hungary. cNEUPRO has now started to select the most promising biomarker candidates from two proteomic studies within cNEUPRO and to reassess the most promising biomarker candidates with larger sample size and independent methods to finally integrate them into novel prototype assays.

To increase the accuracy of a biomarker-based diagnosis, biomarkers in body-fluids have been combined with other biological markers such as structural and functional neuroimaging and neuropsychological testing [91]. Whether the new biomarker assays which will be developed within cNEUPRO will be useful in such a multimodal diagnostic workup remains to be elucidated.

\section{Acknowledgments}

The authors were supported by the cNEUPRO consortium (Stephane Roche, Sylvain Lehmann, Ann Brinkmalm, Nicklas Mattson, David J. Burn, Martin Wiesenfeldt, Edgar da Cruz e Silva, Odete da Cruz e Silva, Arif Malik, Johannes Schuchardt, Carsten Korth, Andreas Müller-Schiffmann, Tuula Pirtilla, Stephan Müllner, Angelika Lüking, Johannes Kornhuber). Financial support came from the European Comission (cNEUPRO, LSHM CT-2007-037950, NeuroTAS, LSHB-CT-2006-037953, Anteprion) and the Landesstiftung Baden Württemberg.

\section{References}

[1] D. S. Knopman, S. T. DeKosky, J. L. Cummings et al., "Practice parameter: diagnosis of dementia (an evidencebased review). Report of the Quality Standards Subcommittee of the American Academy of Neurology," Neurology, vol. 56, no. 9, pp. 1143-1153, 2001.

[2] R. C. Petersen and S. Negash, "Mild cognitive impairment: an overview," CNS Spectrums, vol. 13, no. 1, pp. 45-53, 2008.

[3] R. C. Petersen, G. E. Smith, S. C. Waring, R. J. Ivnik, E. G. Tangalos, and E. Kokmen, "Mild cognitive impairment: clinical characterization and outcome," Archives of Neurology, vol. 56, no. 3, pp. 303-308, 1999.

[4] S. T. DeKosky and K. Marek, "Looking backward to move forward: early detection of neurodegenerative disorders," Science, vol. 302, no. 5646, pp. 830-834, 2003.

[5] L. Davies, B. Wolska, C. Hilbich et al., "A4 amyloid protein deposition and the diagnosis of Alzheimer's disease: prevalence in aged brains determined by immunocytochemistry compared with conventional neuropathologic techniques," Neurology, vol. 38, no. 11, pp. 1688-1693, 1988.
[6] C. R. Jack Jr., V. J. Lowe, S. D. Weigand et al., "Serial PIB and MRI in normal, mild cognitive impairment and Alzheimers disease: implications for sequence of pathological events in Alzheimers disease," Brain, vol. 132, no. 5, pp. 1355-1365, 2009.

[7] M. Citron, "Strategies for disease modification in Alzheimer's disease," Nature Reviews Neuroscience, vol. 5, no. 9, pp. 677685, 2004.

[8] B. Steiner, S. Wolf, and G. Kempermann, "Adult neurogenesis and neurodegenerative disease," Regenerative Medicine, vol. 1, no. 1, pp. 15-28, 2006.

[9] O. Lindvall and Z. Kokaia, "Stem cells in human neurodegenerative disorders - time for clinical translation?" Journal of Clinical Investigation, vol. 120, no. 1, pp. 29-40, 2010.

[10] K. Blennow, H. Hampel, M. Weiner, and H. Zetterberg, "Cerebrospinal fluid and plasma biomarkers in Alzheimer disease," Nature Reviews Neurology, vol. 6, no. 3, pp. 131-144, 2010.

[11] K. Blennow and H. Hampel, "CSF markers for incipient Alzheimer's disease," Lancet Neurology, vol. 2, no. 10, pp. 605613, 2003.

[12] P. Lewczuk and J. Wiltfang, "Neurochemical dementia diagnostics: state of the art and research perspectives," Proteomics, vol. 8, no. 6, pp. 1292-1301, 2008.

[13] C. Brandt, J. C. Bahl, N. H. H. Heegaard, G. Waldemar, and P. Johannsen, "Usability of cerebrospinal fluid biomarkers in a tertiary memory clinic," Dementia and Geriatric Cognitive Disorders, vol. 25, no. 6, pp. 553-558, 2008.

[14] M. Otto, P. Lewczuk, and J. Wiltfang, "Neurochemical approaches of cerebrospinal fluid diagnostics in neurodegenerative diseases," Methods, vol. 44, no. 4, pp. 289-298, 2008.

[15] N. Andreasen, L. Minthon, P. Davidsson et al., "Evaluation of CSF-tau and CSF-A $\beta 42$ as diagnostic markers for Alzheimer disease in clinical practice," Archives of Neurology, vol. 58, no. 3, pp. 373-379, 2001.

[16] K. Blennow, A. Wallin, and O. Hager, "Low frequency of post-lumbar puncture headache in demented patients," Acta Neurologica Scandinavica, vol. 88, no. 3, pp. 221-223, 1993.

[17] E. R. Peskind, R. Riekse, J. F. Quinn et al., "Safety and acceptability of the research lumbar puncture," Alzheimer Disease and Associated Disorders, vol. 19, no. 4, pp. 220-225, 2005.

[18] E. Peskind, A. Nordberg, T. Darreh-Shori, and H. Soininen, "Safety of lumbar puncture procedures in patients with Alzheimer's disease," Current Alzheimer Research, vol. 6, no. 3, pp. 290-292, 2009.

[19] H. Zetterberg, U. Rüetschi, E. Portelius et al., "Clinical proteomics in neurodegenerative disorders," Acta Neurologica Scandinavica, vol. 118, no. 1, pp. 1-11, 2008.

[20] F. Song, A. Poljak, G. A. Smythe, and P. Sachdev, "Plasma biomarkers for mild cognitive impairment and Alzheimer's disease," Brain Research Reviews, vol. 61, no. 2, pp. 69-80, 2009. 
[21] M. A. Korolainen, T. A. Nyman, T. Aittokallio, and T. Pirttilä, "An update on clinical proteomics in Alzheimer's research," Journal of Neurochemistry, vol. 112, no. 6, pp. 1386-1414, 2010.

[22] N. A. Verwey, W. M. van der Flier, K. Blennow et al., "A worldwide multicentre comparison of assays for cerebrospinal fluid biomarkers in Alzheimer's disease," Annals of Clinical Biochemistry, vol. 46, no. 3, pp. 235-240, 2009.

[23] P. Lewczuk, G. Beck, O. Ganslandt et al., "International quality control survey of neurochemical dementia diagnostics," Neuroscience Letters, vol. 409, no. 1, pp. 1-4, 2006.

[24] N. Mattsson, H. Zetterberg, O. Hansson et al., "CSF biomarkers and incipient Alzheimer disease in patients with mild cognitive impairment," Journal of the American Medical Association, vol. 302, no. 4, pp. 385-393, 2009.

[25] A. Petzold, M. D. Chapman, S. Schraen et al., "An unbiased, staged, multicentre, validation strategy for Alzheimer's disease CSF tau levels," Experimental Neurology, vol. 223, no. 2, pp. 432-438, 2010.

[26] C. E. Teunissen, A. Petzold, J. L. Bennett et al., "A consensus protocol for the standardization of cerebrospinal fluid collection and biobanking," Neurology, vol. 73, no. 22, pp. 19141922, 2009.

[27] G. McKhann, D. Drachman, M. Folstein, R. Katzman, D. Price, and E. M. Stadlan, "Clinical diagnosis of Alzheimer's disease: report of the NINCDS-ADRDA work group under the auspices of Department of Health and Human Services Task Force on Alzheimer's disease," Neurology, vol. 34, no. 7, pp. 939-944, 1984.

[28] I. G. McKeith, D. Galasko, K. Kosaka et al., "Consensus guidelines for the clinical and pathologic diagnosis of dementia with Lewy bodies (DLB): report of the consortium on DLB international workshop," Neurology, vol. 47, no. 5, pp. 11131124, 1996.

[29] G. C. Roman, T. K. Tatemichi, T. Erkinjuntti et al., "Vascular dementia: diagnostic criteria for research studies: report of the NINDS-AIREN International Workshop," Neurology, vol. 43, no. 2, pp. 250-260, 1993.

[30] D. Neary, J. S. Snowden, L. Gustafson et al., "Frontotemporal lobar degeneration: a consensus on clinical diagnostic criteria," Neurology, vol. 51, no. 6, pp. 1546-1554, 1998.

[31] J. C. Morris, "The Clinical Dementia Rating (CDR): current version and scoring rules," Neurology, vol. 43, no. 11, pp. 24122414, 1993.

[32] M. F. Folstein, S. E. Folstein, and P. R. McHugh, “"Mini mental state". A practical method for grading the cognitive state of patients for the clinician," Journal of Psychiatric Research, vol. 12, no. 3, pp. 189-198, 1975.

[33] S. Schraen-Maschke, N. Sergeant, C.-M. Dhaenens et al., "Tau as a biomarker of neurodegenerative diseases," Biomarkers in Medicine, vol. 2, no. 4, pp. 363-384, 2008.

[34] V. Welge, O. Fiege, P. Lewczuk et al., "Combined CSF tau, p-tau181 and amyloid- $\beta$ 38/40/42 for diagnosing Alzheimer's disease," Journal of Neural Transmission, vol. 116, no. 2, pp. 203-212, 2009.

[35] M. Bibl, B. Mollenhauer, H. Esselmann et al., "Cerebrospinal fluid neurochemical phenotypes in vascular dementias: original data and mini-review," Dementia and Geriatric Cognitive Disorders, vol. 25, no. 3, pp. 256-265, 2008.

[36] A. Olsson, K. Höglund, M. Sjögren et al., "Measurement of $\alpha$ - and $\beta$-secretase cleaved amyloid precursor protein in cerebrospinal fluid from Alzheimer patients," Experimental Neurology, vol. 183, no. 1, pp. 74-80, 2003.
[37] M. Sjögren, P. Davidsson, J. Gottfries et al., “The cerebrospinal fluid levels of tau, growth-associated protein-43 and soluble amyloid precursor protein correlate in Alzheimer's disease, reflecting a common pathophysiological process," Dementia and Geriatric Cognitive Disorders, vol. 12, no. 4, pp. 257-264, 2001.

[38] A. Post, N. Ackl, M. Rücker et al., "Toward a reliable distinction between patients with mild cognitive impairment and Alzheimer-type dementia versus major depression," Biological Psychiatry, vol. 59, no. 9, pp. 858-862, 2006.

[39] K. Sennvik, J. Fastbom, M. Blomberg, L.-O. Wahlund, B. Winblad, and E. Benedikz, "Levels of $\alpha$ - and $\beta$-secretase cleaved amyloid precursor protein in the cerebrospinal fluid of Alzheimer's disease patients," Neuroscience Letters, vol. 278, no. 3, pp. 169-172, 2000.

[40] W. E. Van Nostrand, S. L. Wagner, W. R. Shankle et al., "Decreased levels of soluble amyloid $\beta$-protein precursor in cerebrospinal fluid of live Alzheimer disease patients," Proceedings of the National Academy of Sciences of the United States of America, vol. 89, no. 7, pp. 2551-2555, 1992.

[41] P. Lewczuk, H. Kamrowski-Kruck, O. Peters et al., "Soluble amyloid precursor proteins in the cerebrospinal fluid as novel potential biomarkers of Alzheimer's disease: a multicenter study," Molecular Psychiatry, vol. 15, no. 2, pp. 138-145, 2010.

[42] E. Portelius, G. Brinkmalm, A. Tran et al., "Identification of novel N-terminal fragments of amyloid precursor protein in cerebrospinal fluid," Experimental Neurology, vol. 223, no. 2, pp. 351-358, 2010.

[43] E. Portelius, G. Brinkmalm, A. J. Tran, H. Zetterberg, A. Westman-Brinkmalm, and K. Blennow, "Identification of novel APP/A $\beta$ isoforms in human cerebrospinal fluid," $\mathrm{Neu}$ rodegenerative Diseases, vol. 6, no. 3, pp. 87-94, 2009.

[44] H.-W. Klafki, P. Lewczuk, H. Kamrowski-Kruck et al., "Measurement of ERK 1/2 in CSF from patients with neuropsychiatric disorders and evidence for the presence of the activated form," Journal of Alzheimer's Disease, vol. 18, no. 3, pp. 613622, 2009.

[45] R. Fukuyama, T. Izumoto, and S. Fushiki, "The cerebrospinal fluid level of glial fibrillary acidic protein is increased in cerebrospinal fluid from Alzheimer's disease patients and correlates with severity of dementia," European Neurology, vol. 46, no. 1, pp. 35-38, 2001.

[46] S. Jesse, P. Steinacker, L. Cepek et al., "Glial fibrillary acidic protein and protein S-100B: different concentration pattern of glial proteins in cerebrospinal fluid of patients with Alzheimer's disease and Creutzfeldt-Jakob disease," Journal of Alzheimer's Disease, vol. 17, no. 3, pp. 541-551, 2009.

[47] M. C. Polidori, H. R. Griffiths, E. Mariani, and P. Mecocci, "Hallmarks of protein oxidative damage in neurodegenerative diseases: focus on Alzheimer's disease," Amino Acids, vol. 32, no. 4, pp. 553-559, 2007.

[48] M. A. Korolainen and T. Pirttilä, "Cerebrospinal fluid, serum and plasma protein oxidation in Alzheimer's disease," Acta Neurologica Scandinavica, vol. 119, no. 1, pp. 32-38, 2009.

[49] J. N. Keller, F. A. Schmitt, S. W. Scheff et al., "Evidence of increased oxidative damage in subjects with mild cognitive impairment," Neurology, vol. 64, no. 7, pp. 1152-1156, 2005.

[50] N. Ahmed, U. Ahmed, P. J. Thornalley, K. Hager, G. Fleischer, and G. Münch, "Protein glycation, oxidation and nitration adduct residues and free adducts of cerebrospinal fluid in Alzheimer's disease and link to cognitive impairment," Journal of Neurochemistry, vol. 92, no. 2, pp. 255-263, 2005. 
[51] M. A. Korolainen, T. A. Nyman, P. Nyyssönen, E. S. Hartikainen, and T. Pirttilä, "Multiplexed proteomic analysis of oxidation and concentrations of cerebrospinal fluid proteins in Alzheimer disease," Clinical Chemistry, vol. 53, no. 4, pp. 657-665, 2007.

[52] H. Tohgi, T. Abe, K. Yamazaki, T. Murata, E. Ishizaki, and C. Isobe, "Alterations of 3-nitrotyrosine concentration in the cerebrospinal fluid during aging and in patients with Alzheimer's disease," Neuroscience Letters, vol. 269, no. 1, pp. 52-54, 1999.

[53] H. Ryberg, A.-S. Söderling, P. Davidsson, K. Blennow, K. Caidahl, and L. I. Persson, "Cerebrospinal fluid levels of free 3-nitrotyrosine are not elevated in the majority of patients with amyotrophic lateral sclerosis or Alzheimer's disease," Neurochemistry International, vol. 45, no. 1, pp. 57-62, 2004.

[54] P. Brechlin, O. Jahn, P. Steinacker et al., "Cerebrospinal fluidoptimized two-dimensional difference gel electrophoresis (2D DIGE) facilitates the differential diagnosis of CreutzfeldtJakob disease," Proteomics, vol. 8, no. 20, pp. 4357-4366, 2008.

[55] P. Steinacker, W. Rist, M. Swiatek-de-Lange et al., "Ubiquitin as potential cerebrospinal fluid marker of Creutzfeldt-Jakob disease," Proteomics, vol. 10, no. 1, pp. 81-89, 2010.

[56] C. Piubelli, M. Fiorini, G. Zanusso et al., "Searching for markers of Creutzfeldt-Jakob disease in cerebrospinal fluid by two-dimensional mapping," Proteomics, vol. 6, pp. S256-S261, 2006.

[57] P. Davidsson, A. Westman-Brinkmalm, C. L. Nilsson et al., "Proteome analysis of cerebrospinal fluid proteins in Alzheimer patients," NeuroReport, vol. 13, no. 5, pp. 611-615, 2002.

[58] K. Iqbal and I. Grundke-Iqbal, "Elevated levels of $\tau$ and ubiquitin in brain and cerebrospinal fluid in Alzheimer's disease," International Psychogeriatrics, vol. 9, no. 1, pp. 289 296, 1997.

[59] T. Kudo, K. Iqbal, R. Ravid, D. F. Swaab, and I. GrundkeIqbal, "Alzheimer disease: correlation of cerebro-spinal fluid and brain ubiquitin levels," Brain Research, vol. 639, no. 1, pp. $1-7,1994$.

[60] K. Blennow, P. Davidsson, A. Wallin, C.-G. Gottfries, and L. Svennerholm, "Ubiquitin in cerebrospinal fluid in Alzheimer's disease and vascular dementia," International Psychogeriatrics, vol. 6, no. 1, pp. 13-22, 1994.

[61] M. Otto, J. Wiltfang, L. Cepek et al., "Tau protein and 143-3 protein in the differential diagnosis of Creutzfeldt-Jakob disease," Neurology, vol. 58, no. 2, pp. 192-197, 2002.

[62] M. Otto, H. Stein, A. Szudra et al., "S-100 protein concentration in the cerebrospinal fluid of patients with CreutzfeldtJakob disease," Journal of Neurology, vol. 244, no. 9, pp. 566570, 1997.

[63] M. Otto, J. Wiltfang, E. Schütz et al., "Diagnosis of CreutzfeldtJakob disease by measurement of S100 protein in serum: prospective case-control study," British Medical Journal, vol. 316, no. 7131, pp. 577-582, 1998.

[64] A. Ladogana, P. Sanchez-Juan, E. Mitrová et al., "Cerebrospinal fluid biomarkers in human genetic transmissible spongiform encephalopathies," Journal of Neurology, vol. 256, no. 10 , pp. $1620-1628,2009$.

[65] E. R. Peskind, W. S. T. Griffin, K. T. Akama, M. A. Raskind, and L. J. Van Eldik, "Cerebrospinal fluid S100B is elevated in the earlier stages of Alzheimer's disease," Neurochemistry International, vol. 39, no. 5-6, pp. 409-413, 2001.

[66] M. L. Chaves, A. L. Camozzato, E. D. Ferreira et al., "Serum levels of S100B and NSE proteins in Alzheimer's disease patients," Journal of Neuroinflammation, vol. 7, article 6, 2010.
[67] P. Steinacker, C. Hendrich, A. D. Sperfeld et al., "TDP-43 in cerebrospinal fluid of patients with frontotemporal lobar degeneration and amyotrophic lateral sclerosis," Archives of Neurology, vol. 65, no. 11, pp. 1481-1487, 2008.

[68] P. Steinacker, C. Hendrich, A.-D. Sperfeld et al., "Concentrations of beta-amyloid precursor protein processing products in cerebrospinal fluid of patients with amyotrophic lateral sclerosis and frontotemporal lobar degeneration," Journal of Neural Transmission, vol. 116, no. 9, pp. 1169-1178, 2009.

[69] M. Mishra, T. Paunesku, G. E. Woloschak et al., "Gene expression analysis of frontotemporal lobar degeneration of the motor neuron disease type with ubiquitinated inclusions," Acta Neuropathologica, vol. 114, no. 1, pp. 81-94, 2007.

[70] M. Bibl, B. Mollenhauer, S. Wolf et al., "Reduced CSF carboxyterminally truncated $\mathrm{A} \beta$ peptides in frontotemporal lobe degenerations," Journal of Neural Transmission, vol. 114, no. 5, pp. 621-628, 2007.

[71] M. Bibl, B. Mollenhauer, P. Lewczuk et al., "Validation of amyloid- $\beta$ peptides in CSF diagnosis of neurodegenerative dementias," Molecular Psychiatry, vol. 12, no. 7, pp. 671-680, 2007.

[72] M. Riemenschneider, S. Wagenpfeil, J. Diehl et al., "Tau and $A \beta 42$ protein in CSF of patients with frontotemporal degeneration," Neurology, vol. 58, no. 11, pp. 1622-1628, 2002.

[73] M. Sjögren, P. Davidsson, A. Wallin et al., "Decreased CSF$\beta$-amyloid 42 in Alzheimer's disease and amyotrophic lateral sclerosis may reflect mismetabolism of $\beta$-amyloid induced by disparate mechanisms," Dementia and Geriatric Cognitive Disorders, vol. 13, no. 2, pp. 112-118, 2002.

[74] H. Bian, J. C. Van Swieten, S. Leight et al., "CSF biomarkers in frontotemporal lobar degeneration with known pathology," Neurology, vol. 70, no. 19, pp. 1827-1835, 2008.

[75] Y. A. L. Pijnenburg, J. C. Janssen, N. S. M. Schoonenboom et al., "CSF neurofilaments in frontotemporal dementia compared with early onset Alzheimer's disease and controls," Dementia and Geriatric Cognitive Disorders, vol. 23, no. 4, pp. 225-230, 2007.

[76] L. Parnetti, P. Tiraboschi, A. Lanari et al., "Cerebrospinal fluid biomarkers in Parkinson's disease with dementia and dementia with Lewy bodies," Biological Psychiatry, vol. 64, no. 10, pp. 850-855, 2008.

[77] S. Jesse, P. Steinacker, S. Lehnert, F. Gillardon, B. Hengerer, and M. Otto, "Neurochemical approaches in the laboratory diagnosis of Parkinson and Parkinson dementia syndromes: a review," CNS Neuroscience and Therapeutics, vol. 15, no. 2, pp. 157-182, 2009.

[78] C. Balducci, L. Pierguidi, E. Persichetti et al., "Lysosomal hydrolases in cerebrospinal fluid from subjects with Parkinson's disease," Movement Disorders, vol. 22, no. 10, pp. 14811484, 2007.

[79] L. Parnetti, C. Balducci, L. Pierguidi et al., "Cerebrospinal fluid $\beta$-glucocerebrosidase activity is reduced in Dementia with Lewy Bodies," Neurobiology of Disease, vol. 34, no. 3, pp. 484486, 2009.

[80] P. Lewczuk, J. Kornhuber, E. Vanmechelen et al., "Amyloid $\beta$ peptides in plasma in early diagnosis of Alzheimer's disease: a multicenter study with multiplexing," Experimental Neurology, vol. 223, no. 2, pp. 366-370, 2010.

[81] J.-C. Lambert, S. Schraen-Maschke, F. Richard et al., "Association of plasma amyloid $\beta$ with risk of dementia: the prospective Three-City Study," Neurology, vol. 73, no. 11, pp. 847-853, 2009.

[82] M. C. Irizarry, "Biomarkers of Alzheimer disease in plasma," NeuroRx, vol. 1, no. 2, pp. 226-234, 2004. 
[83] P. Schneider, H. Hampel, and K. Buerger, "Biological marker candidates of alzheimer's disease in blood, plasma, and serum," CNS Neuroscience and Therapeutics, vol. 15, no. 4, pp. 358-374, 2009.

[84] O. Hansson, H. Zetterberg, E. Vanmechelen et al., "Evaluation of plasma $\mathrm{A} \beta_{40}$ and $\mathrm{A} \beta_{42}$ as predictors of conversion to Alzheimer's disease in patients with mild cognitive impairment," Neurobiology of Aging, vol. 31, no. 3, pp. 357-367, 2010.

[85] M. Bibl, H. Esselmann, B. Mollenhauer et al., "Blood-based neurochemical diagnosis of vascular dementia: a pilot study," Journal of Neurochemistry, vol. 103, no. 2, pp. 467-474, 2007.

[86] J. M. Maler, H.-W. Klafki, S. Paul et al., "Urea-based two-dimensional electrophoresis of beta-amyloid peptides in human plasma: evidence for novel A $\beta$ species," Proteomics, vol. 7, no. 20, pp. 3815-3820, 2007.

[87] J. M. Maler, P. Spitzer, H.-W. Klafki et al., "Adherencedependent shifts in the patterns of $\beta$-amyloid peptides secreted by human mononuclear phagocytes," Brain, Behavior, and Immunity, vol. 22, no. 7, pp. 1044-1048, 2008.

[88] J. M. Maler, P. Spitzer, H.-W. Klafki et al., "Distinct fractional $\mathrm{A} \beta$ release patterns in human mononuclear phagocytes," Journal of Neuroimmunology, vol. 206, no. 1-2, pp. 1-4, 2009.

[89] S. Roche, A. Gabelle, and S. Lehmann, "Clinical proteomics of the cerebrospinal fluid: towards the discovery of new biomarkers," Proteomics_Clinical Applications, vol. 2, no. 3, pp. 428-436, 2008.

[90] S. Roche, L. Tiers, M. Provansal et al., "Depletion of one, six, twelve or twenty major blood proteins before proteomic analysis: the more the better?" Journal of Proteomics, vol. 72, no. 6, pp. 945-951, 2009.

[91] K. B. Walhovd, A. M. Fjell, J. Brewer et al., "Combining MR imaging, positron-emission tomography, and CSF biomarkers in the diagnosis and prognosis of Alzheimer disease," American Journal of Neuroradiology, vol. 31, no. 2, pp. 347-354, 2010. 


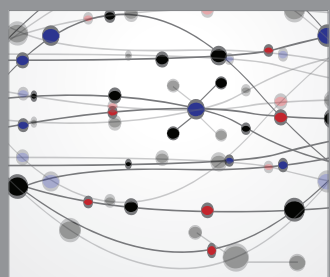

The Scientific World Journal
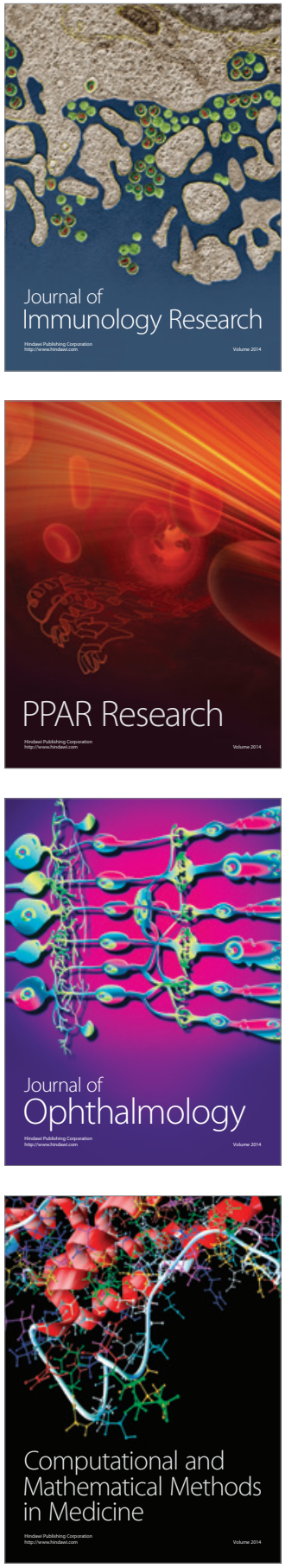

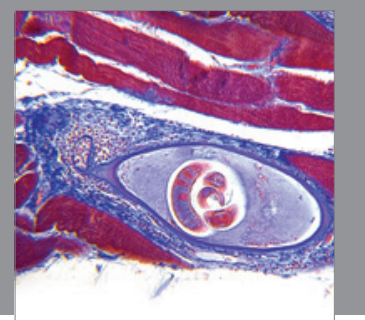

Gastroenterology

Research and Practice
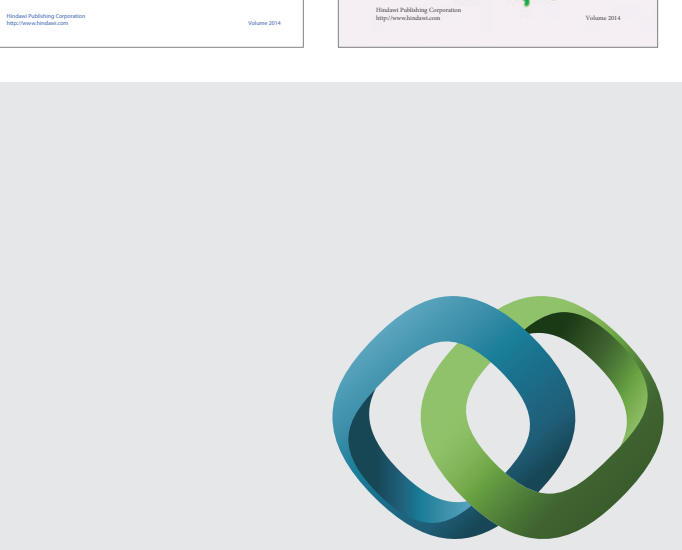

\section{Hindawi}

Submit your manuscripts at

http://www.hindawi.com
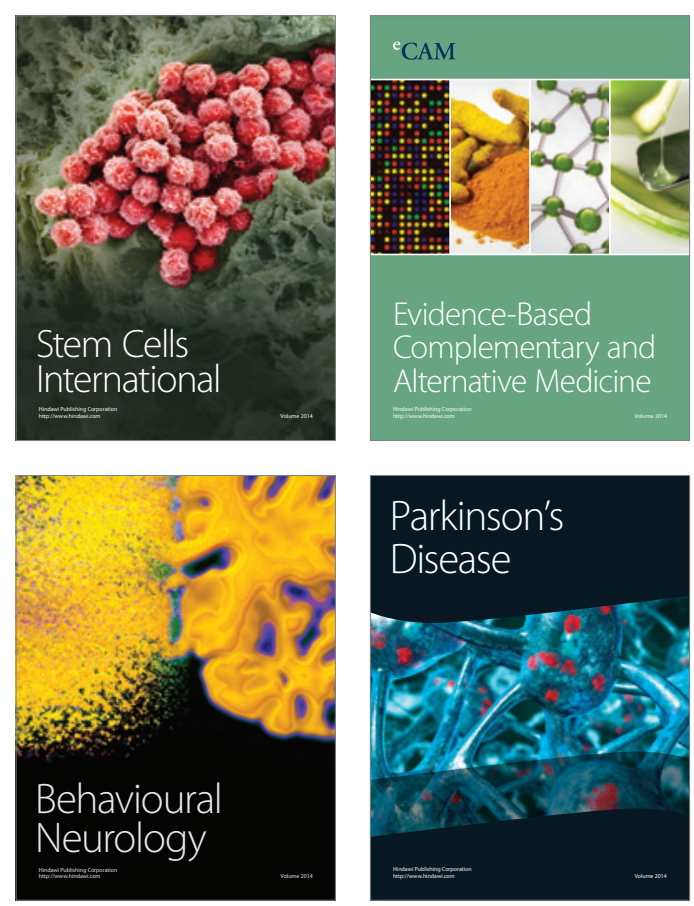

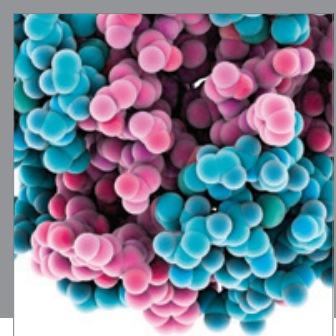

Journal of
Diabetes Research

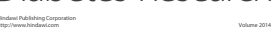

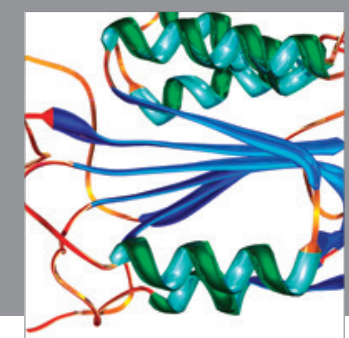

Disease Markers
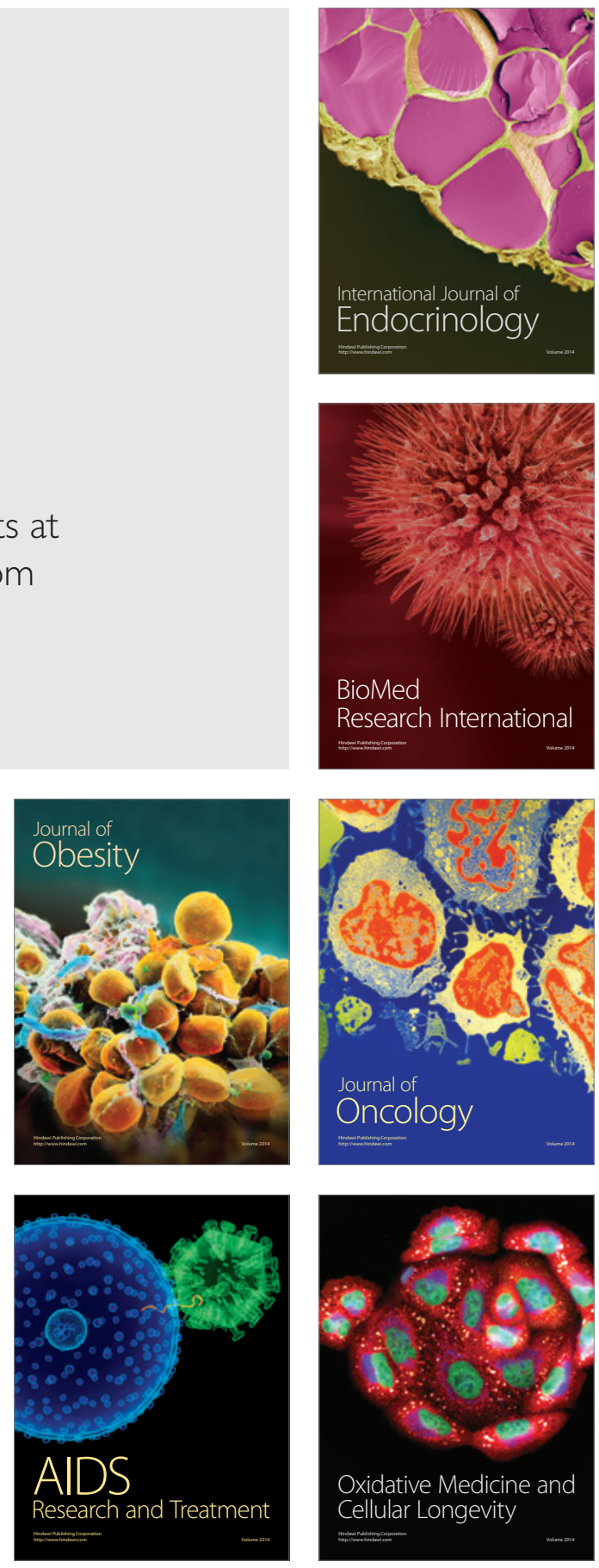